\title{
Compliance among a group of Egyptian elderly in Cairo
}

\section{Reham S. Radwan ${ }^{a}$, Essam M. Helalb. Ghada E. El-Din Aminc, and Salma M. El Said}

a Family medicine specialist, Egyptian Ministry of Health and Population

b Professor of General Internal Medicine, Faculty of Medicine, Ain Shams University, Cairo, Egypt

c Assistant professor of Community Environment \& Occupational Medicine department, Faculty of Medicine, Ain Shams University, Cairo, Egypt

d Assistant professor of Geriatric Medicine \&Gerontology, Faculty of Medicine, Ain Shams University, Cairo, Egypt

\section{Abstract}

Background: adherence represents significant challenges to healthcare professionals especially among elderly.

Aim: The study aimed to compare compliance among elderly in nursing homes and community dwelling.

Methods: This cross-sectional study was conducted on the elderly of community dwelling $(n=200)$ and nursing homes $(n=200)$ in Cairo, Egypt. The study data were collected between February 2017 to February 2018. For data collection, Medication Assessment Questionnaire (MAQ) was used. The data were evaluated with SPSS for 22.0 Windows statistical package program. Data descriptive statistics were evaluated with independent $t$ test and the chisquare test.

Results: The majority of participants of the 2 groups are at age 60-70 years. According to the study results, most of the participants in the 2 groups are medium adherent.

Conclusions: there is no difference in adherence between community dwelling and nursing homes elderly.

Keywords: adherence, compliance, Egyptian elderly, elderly

\section{Background}

Adherence was defined by WHO as "the extent to which a person's behavior (taking medication, following a diet, and/or executing lifestyle changes) corresponds with agreed recommendations from a health care provider". "It also stated that more than fifty percent of the drugs prescribed, dispensed or sold worldwide were used in a wrong way. ${ }^{2}$

Adherence and compliance are often used interchangeably but there is difference between these two terms which make adherence is the preferred terminology by some authors: adherence emphasizes the patient-provider relationship, requires motivation and competence on behalf of the patient, allows for open dialogue and addresses underlying reasons contributing to non-adherence, and continued follow-up is an essential component of the plan. While compliance deals with patient in a parental way and does not incorporate a "therapeutic relationship", represents actual adoption of lifestyle change behaviors and medication-taking, focuses on what the patient is "told to do" and whether they comply or not, and does not incorporate follow-up to assess patient progress. ${ }^{3}$ In the literature, the rates of non-adherence around the world range from 7.1 to $66.2 \%$ as adherence represents significant challenges. ${ }^{4}$ The rate of medication adherence at a range of $38-57 \%$ with an average rate of less than $45 \%$ in older Populations. ${ }^{5}$ As $33-50 \%$ of patients do not adhere to their medication regimens as prescribed. $^{6}$ Furthermore, one-half of filled prescriptions in daily clinical practice are incorrectly taken. ${ }^{7}$ Non adherence to hypertensive treatment was 9.0\% in United States and Scotland, $54.2 \%$ in Palestine, $47.5 \%$ in Taiwan, $47.0 \%$ in Saudi Arabia, $64.7 \%$ in Pakistan, $55.8 \%$ in Malaysia, $35.4 \%$ in Ethiopia, $73 \%$ in Gambia and $25.9 \%$ in Egypt ${ }^{9,8}$. WHO reported that average rate of adherence is around $50 \%$ in chronic patients in developed countries and expected to be lower in developing countries. ${ }^{1}$ In Egyptian diabetic 
patients only $38.9 \%$ were adherent to their oral hypoglycemic drugs, Moreover, lowest rate of adherence was reported in elderly patients $28.1 \%$ than other age groups. ${ }^{10}$ Egyptian patients with asthma and COPD, adherence rates were $8.5 \%$ and $7 \%$ respectively. ${ }^{11}$ Medication non-adherence costs as much as $\$ 100$ billion per year in the United States. ${ }^{12}$

Adherence measures can be classified as subjective and objective or as direct and indirect. Both categories are not different in achieved outcomes, they are only different in the method of collecting information. The subjective method relays on provider's or patient's reporting of their medication-taking behavior but patients tend to give false answers to avoid disapproval by the health care provider. While the objective method depends on biochemical measures, electronic monitoring, pill counting and secondary database analysis which is considered a better method than subjective measures. $^{13}$

Direct method includes measuring the drug or its metabolite in body fluids, such as urine or blood, measuring the biologic marker of the drug and direct observation of patient's medication-taking behavior. This makes this method most accurate but don't provide any information about the pattern of the nonadherence or what causes it, patients can hide their pills under tongue and throw them later, expensive, difficult to perform and patient feeling anxious which leads to "white coat adherence" which means improved patient adherence to treatment around clinic visits. ${ }^{14}$

Indirect method includes patient questionnaires, selfreports, pill count, pharmacy refill records, assessment of the patient's clinical response, electronic medication monitors, measurement of physiological markers (as heart rate in patients on beta-blockers) and patient diaries. ${ }^{15}$

The drawbacks of indirect methods are that their results can be easily altered by the patient, pill count is unreliable due to "pill dumping" which takes place by the patients when the physician suspects nonadherence, pharmacy records not indicator to ingestion of medication and needs a closed pharmacy system, clinical response can be affected by other factors, electronic methods are expensive and mandate follow up visits and downloading data from medication vials and other reasons can affect the level of physiological markers. Although particular methods of adherence measures may be preferred in specific clinical or research settings, the best way is to combine more than one method to maximize accuracy. ${ }^{16}$

Advantages of patient self-reports are brief, cheap, acceptable to patients, easy to administer, valid, nonintrusive, can distinguish between different types of non-adherence, and able to provide information on attitudes and beliefs about medication. Different nature of the diseases, makes no gold-standard scale for measuring medication adherence, but the best known and most widely used is a Medication Adherence Questionnaire (MAQ) which is the shortest, easiest to score and very adaptable for different groups of medication. ${ }^{17}$ our aim in this study is to compare compliance among elderly in nursing homes and community dwelling.

\section{Methods}

A cross-sectional Study where data was collected between February 2017 to February 2018.

Study setting: Elderly living either at community dwelling (outpatient geriatric clinic at Ain Shams University Hospital and El Shams sporting club) or in nursing homes in Cairo $(\mathrm{n}=200)$.

Sampling and sample size: In determining the sample size for the elderly, it was found to be 400 elderly putting in consideration proportion of persons $50 \% \pm 5$ at $95 \%$ C.I using Epi Info7 program. It was divided to 200 participants from nursing homes and 200 participants from community dwelling (100 participants from the outpatient geriatric clinic and 100 participants from geriatric club).

No sampling method was used for sample selection of the elderly living in the nursing homes. Anyone agreed to participate in the study was included $(n=200)$. Similarly, the elderly attending the sporting club every Monday of the week for social activities were included $(n=100)$. While the participants of the geriatric outpatient clinic were selected by including every 3rd participant -which was randomly selected- attending every day of the week $(n=100)$.

Data were collected through face-to-face interviews with the individuals during visits to geriatric outpatient clinic, club and 6 nursing homes. In addition, individuals were verbally informed of the study.

Inclusion criteria: Individuals aged 60 and over.

Exclusion criteria: Any elderly with dementia or any mental disease, with severe psychological problems, or totally dependent elderly on a caregiver in taking his her medication was excluded from the study and those who did not want to participate in the study.

Study tools: Every participant was subjected to extraction sheet containing demographic data (age, gender), socioeconomic data (pre-retirement occupation, social status, monthly income) and educational level. Mini Mental State Examination (MMSE) Arabic version ${ }^{18}$, Geriatric Depression Scale (GDS 15) ${ }^{19}$, Activity of Daily Living(ADL) ${ }^{20}$ and Instrumental Activity of Daily living(IADL) ${ }^{21}$. For evaluation of medication adherence, a validated interview questionnaire "the Morisky, Green, and Levine (MGL) Adherence Scale" or "Medication Assessment Questionnaire (MAQ)" 22 which consists of 4 questions having a binary answer. Each "no", response is rated as 1 and each "yes" response is rated as 0 . Participants are classified as low adherent if they have $0-1$ points, medium adherent if they have 2-3 points and high adherent if they have 4 points. Using this tool was approved by professor Morisky through email communication.

Statistical analysis: The statistical analysis of the research was performed with the SPSS 22.0 package 
program. Descriptive statistics were carried out for all variables and expressed as mean and \pm SD for quantitative data, whereas qualitative data were expressed as numbers and percentages. For quantitative data: comparison between groups' mean age was done by using independent $t$ test while for qualitative data: comparison between groups' categories levels was done using chi-square test. A $\mathrm{P}$ value of $\leq 0.05$ was chosen as a level of significance and $\leq 0.01$ as a level of high significance.

\section{Results}

Regarding sociodemographic data of the participants; the majority of the participants were at $60-70$ years old (73.5\% in community dwelling and $51.5 \%$ in nursing homes) with higher mean age among nursing home participants 71.4. Females represent the majority of our sample with higher percent among nursing home participanRegarding the social status, the majority of community dwelling participants were married $110(55 \%)$ while the majority of nursing home participants were widows $115(57.5 \%)$. In both groups the majority were ex-employee $(54.3 \%, 41 \%)$, non or ex-smokers $(88.5 \%, 81 \%)$, and had university education $(29.5 \%, 38 \%)$ in community dwelling and nursing homes respectively. The monthly income of the majority of nursing home participants (3000-<4000 EP) $(28.5 \%)$ was higher than that of community dwelling participants (<1000 EP) (23\%) (Table 1,2).
Table 1: Age distribution among all participants: group 1 (community dwelling) and group 2 (nursing homes)

\begin{tabular}{llll}
\hline $\begin{array}{l}\text { Age } \\
\text { (years) }\end{array}$ & Group 1 & Group 2 & P value \\
\hline $\mathbf{6 0 - 7 0}$ & $147(73.5 \%)$ & $103(51.5 \%)$ & $0.000^{*}$ \\
$\mathbf{7 0 - 8 0}$ & $52(26 \%)$ & $66(33 \%)$ & \\
$>\mathbf{8 0}$ & $1(0.5 \%)$ & $31(15.5 \%)$ & \\
Mean \pm & $68.04 \pm 5.3$ & $71.43 \pm 8.5$ & \\
SD & & & \\
\hline
\end{tabular}

Table (3): Medication Assessment Questionnaire (MAQ) categories for adherence in all participants

\begin{tabular}{lll}
\hline $\begin{array}{l}\text { MAQ categories } \\
\text { Low adherence }\end{array}$ & $\mathrm{N}$ & $\%$ \\
& 139 & $33.8 \%$ \\
Medium adherence & 171 & $41.6 \%$ \\
High adherence & 90 & $21.9 \%$ \\
\hline
\end{tabular}

Regarding drug adherence; The majority of our participants in both groups 171(41.6\%) were medium adherent followed by $139(33.8 \%)$ low adherent and the least $90(21.9 \%)$ was high adherent (Table 3).

Table (2): Socio-demographic characteristics among the participants in both groups

\begin{tabular}{|c|c|c|c|c|c|c|c|}
\hline \multirow[t]{2}{*}{ Items } & & \multicolumn{2}{|l|}{ Group 1} & \multicolumn{2}{|l|}{ Group 2} & \multirow[t]{2}{*}{ Total } & \multirow[t]{2}{*}{$\mathrm{P}^{*}$} \\
\hline & & Number & Percent & Number & Percent & & \\
\hline \multirow[t]{2}{*}{ Gender } & Male & 90 & $45 \%$ & 56 & $28 \%$ & 146 & \multirow[t]{2}{*}{$.000 *$} \\
\hline & Female & 110 & $55 \%$ & 144 & $72 \%$ & 254 & \\
\hline Social & Single & 1 & $0.5 \%$ & 15 & $7.5 \%$ & 16 & \multirow[t]{4}{*}{$.000 *$} \\
\hline \multirow[t]{3}{*}{ Status } & Married & 110 & $55 \%$ & 38 & $19 \%$ & 148 & \\
\hline & Widow & 79 & $39.5 \%$ & 115 & $57.5 \%$ & 194 & \\
\hline & Divorced & 10 & $5 \%$ & 32 & $16 \%$ & 42 & \\
\hline \multirow{4}{*}{$\begin{array}{l}\text { Pre-retirement } \\
\text { occupation }\end{array}$} & Housewife & 49 & $24.6 \%$ & 77 & $38.5 \%$ & 127 & \multirow[t]{4}{*}{$.006 *$} \\
\hline & $* *$ Skilled job & 25 & $12.6 \%$ & 17 & $8.5 \%$ & 42 & \\
\hline & ***Employee & 108 & $54.3 \%$ & 82 & $41 \%$ & 190 & \\
\hline & Private sector & 17 & $8.5 \%$ & 24 & $12 \%$ & 41 & \\
\hline \multirow{6}{*}{$\begin{array}{l}\text { Educational } \\
\text { level }\end{array}$} & Illiterate & 48 & $24 \%$ & 40 & $20 \%$ & 88 & \multirow[t]{6}{*}{$.038 *$} \\
\hline & Read and write & 33 & $16.5 \%$ & 16 & $8 \%$ & 49 & \\
\hline & Primary/preparatory & 21 & $10.5 \%$ & 22 & $11 \%$ & 43 & \\
\hline & Secondary/technical school & 37 & $18.5 \%$ & 46 & $23 \%$ & 83 & \\
\hline & University & 59 & $29.5 \%$ & 76 & $38 \%$ & 135 & \\
\hline & Post graduate & 2 & $1 \%$ & 0 & $0 \%$ & 2 & \\
\hline \multirow{2}{*}{\multicolumn{2}{|c|}{ Non smokers }} & 23 & $11.5 \%$ & 38 & $19 \%$ & 61 & \multirow[t]{2}{*}{$.037 *$} \\
\hline & & 177 & $88.5 \%$ & 162 & $81 \%$ & 339 & \\
\hline \multirow{6}{*}{$\begin{array}{l}\text { Monthly } \\
\text { income }\end{array}$} & $<1000 \mathrm{EP}$ & 46 & $23 \%$ & 8 & $4 \%$ & 54 & \multirow[t]{6}{*}{$.000 *$} \\
\hline & $1000-<2000 \mathrm{EP}$ & 38 & $19 \%$ & 48 & $24 \%$ & 86 & \\
\hline & $2000-<3000 \mathrm{EP}$ & 40 & $20 \%$ & 32 & $16 \%$ & 72 & \\
\hline & $3000-<4000 \mathrm{EP}$ & 33 & $16.5 \%$ & 57 & $28.5 \%$ & 90 & \\
\hline & $4000-<5000 \mathrm{EP}$ & 16 & $8 \%$ & 23 & $11.5 \%$ & 39 & \\
\hline & $5000 \mathrm{EP}$ or more & 27 & $13.5 \%$ & 32 & $16 \%$ & 59 & \\
\hline
\end{tabular}

*P value was calculated using chi- square.**like tailor, mechanic, carpenter, electrician, driver .

***Governmental job 
Table (4): Comparison between the 2 groups; group 1

(community dwelling) and group 2 (nursing homes)

regarding their $M A Q$ categories

\begin{tabular}{|c|c|c|c|}
\hline $\begin{array}{l}\text { MAQ } \\
\text { categories }\end{array}$ & Group 1 & $\begin{array}{l}\text { Group } \\
2\end{array}$ & $\mathrm{P}^{*}$ \\
\hline $\begin{array}{l}\text { Low } \\
\text { adherence }\end{array}$ & $67(33.5 \%)$ & $\begin{array}{c}72 \\
(36 \%)\end{array}$ & .775 \\
\hline $\begin{array}{l}\text { Medium } \\
\text { adherence }\end{array}$ & $89(44.5 \%)$ & $\begin{array}{c}82 \\
(41 \%)\end{array}$ & \\
\hline $\begin{array}{l}\text { High } \\
\text { adherence }\end{array}$ & $44(22 \%)$ & $\begin{array}{c}46 \\
(23 \%)\end{array}$ & \\
\hline
\end{tabular}

In table 4 there was no significant difference regarding adherence between community dwelling participants and nursing homes participants.

In assessing the questions of Medication Assessment Questionnaire (MAQ); each "no" answer reflects good adherence. The answers of the question (Do you ever forget to take your medicine?) were significant better answer "no" among community dwelling participants $104(52 \%)$ compared to that of nursing homes participants $122(30.5 \%)$, but the majority of the 2 groups $62.5-53 \%$ answered "no" to the question (Are you careless at times about taking your medicine?) with better significant difference among community dwelling participants. Regarding the question (When you feel better, do you sometimes stop taking your medicine?) both groups participants answered "yes" $60.5-58.5 \%$ but without significant difference between them. On the contrary both groups participants 53$65.5 \%$ answered "no" to the question (Sometimes if you feel worse when you take the medicine, do you stop taking it?) with better significant difference in community dwelling participants (table 5).

Table (5): Comparison between the 2 groups; group 1 (community dwelling) and group 2 (nursing homes) regarding their MAQ items

\begin{tabular}{lclll}
\hline MAQ items & & \multicolumn{2}{c}{ Groups } & \multirow{2}{*}{$\mathbf{P}^{*}$} \\
\cline { 2 - 4 } Item 1 & $\mathrm{Y}$ & \multicolumn{1}{c}{ Group 1 } & Group 2 & \\
& $\mathrm{N}$ & $104(52 \%)$ & $78(39 \%)$ & $.043 *$ \\
Item 2 & $\mathrm{Y}$ & $75(37.5 \%)$ & $94(47 \%)$ & $.034 *$ \\
& $\mathrm{~N}$ & $125(62.5 \%)$ & $106(53 \%)$ & \\
Item 3 & $\mathrm{Y}$ & $121(60.5 \%)$ & $117(58.5 \%)$ & .380 \\
& $\mathrm{~N}$ & $79(39.5 \%)$ & $83(41.5 \%)$ & \\
Item 4 & $\mathrm{Y}$ & $75(37.5 \%)$ & $94(47 \%)$ & $.034 *$ \\
& $\mathrm{~N}$ & $125(62.5 \%)$ & $106(53 \%)$ & \\
\hline
\end{tabular}

${ }^{*} \mathrm{P}$ value was calculated using chi- square.

\section{Discussion}

In the study, it was found that the mean age among nursing home participants was higher as they need more care than younger elderly which can be offered by nursing homes. The majority of our participants were females as they were more cooperative and willing to participate in the study. Also the majority of nursing home participants were widows and in the literature there are studies indicating that the elderly who lost their spouses or who are still single prefer to stay in nursing homes either because they do not want to live alone or because they have been left alone. ${ }^{23,24}$ The higher monthly income of the majority of nursing home participants is understandable as living in a nursing home costs the elderly more money.

The majority of the elderly were medium adherent, low, and high adherent which is the same finding by Rajpura and Nayakand and considered unsatisfying result but lack of adherence is contributed to different factors and that necessitates the importance of more assessment of adherence predicators in the Middle East ${ }^{25}$ This was not in line with the finding of a cross sectional study done on self-neglect elderly to determine whether medication regimen complexity predicts medication adherence levels, in which the majority of the participants were low adherent followed by medium adherent and no participant was high adherent. This difference in results may be due to using the Morisky Medication Adherence Scale (MMAS -8) in the latter study- which has different categorical scores and the participants were specifically chosen self-neglect. ${ }^{26}$

The better significant answers of the community dwelling participants in $1^{\text {st }}$ question of MAQ questionnaire was expected as their mean age is lower making memory dysfunction less evident. While, the insignificant difference in the answer of the $3^{\text {rd }}$ question between the 2 groups indicates indicating incorrect medication taking behavior in response to improvement to their medications. On the contrary better significant difference in community dwelling participants' answers to $4^{\text {th }}$ question was expected as half of them (100) were interviewed in outpatient clinic seeking medical care with better medical information.

\section{Conclusion:}

Although there was no difference in adherence between community dwelling and nursing homes elderly but their medication adherence was not satisfying which necessitates using appropriate, effective intervention to improve medication adherence especially among elderly as they have several sensory, motor and intellectual dysfunctions.

The Middle East lacks information about medication adherence in general and specifically in elderly and that mandates more studies to be carried out in such field.

\section{Conflict of Interests}

The author has no conflict of interests to declare regarding the publication of this paper. 


\section{Study limitations:}

There were difficulties in getting the approval of the administration of many nursing homes (either governmental or private) to participate in the study even after knowing that this study is not related to any governmental institution or any media.

The question about the monthly income made a number of participants uncomfortable to answer which may affect their honesty in giving the true answer and hence this question was postponed to be asked at the end of the interview.

\section{References}

1- Sabaté E. Adherence to long-term therapies: evidence for action. World Health Organization; 2003:7

2- World Health Organization. The pursuit of responsible use of medicines: sharing and learning from country experiences. World Health Organization; 2012:1

3- Dixon DL, Bolick JP, Godishala LM, Kris-Etherton PM, Nash DT, Neri L, Warren WS. Clinician's toolkit: a guide to medication and lifestyle adherence. Lipid Spin 2013;11(suppl 1):1-20.

4- Pérez-Jover V, Mira J, Carratala-Munuera C, GilGuillen V, Basora J, López-Pineda A, Orozco-Beltrán D. Inappropriate use of medication by elderly, polymedicated, or multipathological patients with chronic diseases. International journal of environmental research and public health. 2018 Feb 10;15(2):310.

5- Kim S, Bennett K, Wallace E, Fahey T, Cahir C. Measuring medication adherence in older communitydwelling patients with multimorbidity. European journal of clinical pharmacology. 2018 Mar 1;74(3):357-64.

6- Munger MA, Van Tassell BW, LaFleur J. Medication nonadherence: an unrecognized cardiovascular risk factor. Medscape general medicine. 2007;9(3):58.

7- MacLaughlin EJ, Raehl CL, Treadway AK, Sterling TL, Zoller DP, Bond CA. Assessing medication adherence in the elderly. Drugs \& aging. 2005 Mar 1;22(3):231-55.

8- Al-Ramahi R. Adherence to medications and associated factors: A cross-sectional study among Palestinian hypertensive patients. J Epidemiol Glob Health. 2015 Jun 1;5(2):125-32.

9- Asgedom SW, Atey TM, Desse TA. Antihypertensive medication adherence and associated factors among adult hypertensive patients at Jimma University Specialized Hospital, southwest Ethiopia. BMC research notes. $2018 \mathrm{Dec} ; 11(1): 27$.

10- Shams ME, Barakat EA. Measuring the rate of therapeutic adherence among outpatients with T2DM in Egypt. Saudi Pharmaceutical Journal. 2010 Oct 1;18(4):225-32.

11- Galal IH, Mohammad YM, Nada AA, Mohran YE. Medication adherence and treatment satisfaction in some Egyptian patients with chronic obstructive pulmonary disease and bronchial asthma. Egyptian Journal of Bronchology. 2018 Jan 1;12(1):33.

12- Hutchison LC, Jones SK, West DS, Wei JY. Assessment of medication management by communityliving elderly persons with two standardized assessment tools: a cross-sectional study. The American journal of geriatric pharmacotherapy. 2006 Jun 1;4(2):144-53.

13- Lam WY, Fresco P. Medication adherence measures: an overview. BioMed research international. 2015.

14- Al Solami F. Factors affecting antihypertensive medications adherence among hypertensive patients attending a general hospital in Jeddah City, Saudi
Arabia (Doctoral dissertation, Queensland University of Technology).

15- Roy NT, Sajith M, Bansode MP. Assessment of Factors Associated with Low Adherence to Pharmacotherapy in Elderly Patients. Journal of Young Pharmacists. 2017 Apr 1;9(2).

16- Osterberg L, Blaschke T. Adherence to medication. New England journal of medicine. 2005 Aug 4;353(5):487-97.

17- Culig J, Leppée M. From Morisky to Hill-bone; selfreports scales for measuring adherence to medication. Collegium antropologicum. 2014 Mar 31;38(1):55-62.

18- El OkI MA. Prevalence of Alzheimer dementia and other causes of dementia in Egyptian elderly [Dissertation]. Cairo: Ain Shams University. 2002.

19- Yesavage JA, Brink TL, Rose TL, Lum O, Huang V, Adey M, Leirer VO. Development and validation of a geriatric depression screening scale: a preliminary report. Journal of psychiatric research. 1982 Jan 1:17(1):37-49

20- Katz S. Assessing self-maintenance: activities of daily living, mobility, and instrumental activities of daily living. Journal of the American Geriatrics Society. 1983 Dec;31(12):721-7.

21- Lawton MP, Brody EM. Assessment of older people: self-maintaining and instrumental activities of daily living. The gerontologist. 1969 Oct 1;9(3 Part_1):179 86.

22- Morisky DE, Green LW, Levine DM. Concurrent and predictive validity of a self-reported measure of medication adherence. Medical care. 1986 Jan 1:67-74.

23- Demet MM, Taşkin EO, Deniz F, Karaca N, Icelli I. Depressive symptomatology among elderly residential home residents in Manisa: Prevalence and related risk factors. Turk psikiyatri dergisi $=$ Turkish journal of psychiatry. 2002;13(4):290-9.

24- Sütoluk Z, Demirhindi $H$, Savaş N, Akbaba M. Prevalence and causes of depression among elders who live in residential homes in Adana. Turkish Journal of Geriatrics. 2004;7(3):148-51.

25- Rajpura J, Nayak R. Medication adherence in a sample of elderly suffering from hypertension: evaluating the influence of illness perceptions, treatment beliefs, and illness burden. Journal of Managed Care Pharmacy. 2014 Jan;20(1):58-65.

26- Abada S, Clark LE, Sinha AK, Xia R, Pace-Murphy K Flores RJ, Burnett J. Medication Regimen Complexity and Low Adherence in Older Community-Dwelling Adults with Substantiated Self-Neglect. Journal of Applied Gerontology. 2017 Jun 1:0733464817714565. 